\title{
Is Preeclampsia a Protein Misfolding and Aggregation Disease?
}

\author{
Shi-Bin Cheng
}

Department of Pediatrics, Women \& Infants Hospital, Alpert Medical School, Brown University, Providence, RI 02903, USA

*Corresponding author: Shi-Bin Cheng, Department of Pediatrics, Women \& Infants Hospital, Alpert Medical School, Brown University, Providence, RI 02903, USA, Tel: 401-274-1122; E-mail: shibin_cheng@brown.edu

Rec date: Jun 14, 2014; Acc date: Jun 16, 2014; Pub date: Jun 18, 2014

Copyright: $\odot 2014$ Cheng SB. This is an open-access article distributed under the terms of the Creative Commons Attribution License, which permits unrestricted use, distribution, and reproduction in any medium, provided the original author and source are credited.

\section{Editorial}

Preeclampsia (PE) affects 5-8\% of all pregnancies worldwide. It is a pregnancy-specific syndrome characterized by hypertension, proteinuria, edema as well as intrauterine growth restriction. The lack of reliable methods for early diagnosis prior to clinical onset limits the opportunities for prevention and timely treatment of PE. Moreover, there is no efficacious therapy except for delivery. Thus, PE contributes significantly to maternal, fetal and neonatal morbidity and mortality as well as future risk of cardiovascular disease in mother and offspring. The etiology of PE is multifactorial and still remains enigmatic. Many pathways including hypoxia/ischemia at the maternal-fetal interface, antiangiogenic factors, elevated maternal inflammatory response, autoantibodies, and oxidative stress contribute to the pathogenesis of $\mathrm{PE}$ by negatively influencing trophoblast invasion, endothelial function, spiral artery remodeling and placental perfusion [1-3]. The availability of predictive assays and pregnancy-specific pre-clinical models would likely contribute to identification of novel functional biomarkers and development of diagnostic, prophylactic and therapeutic modalities needed to combat this disorder. Although several rodent models have been reported [4], there is still a lack of a well defined animal model that can recapitulate the full spectrum of PE-like features. We have recently established a serum-based "humanized" mouse model that recapitulates all the features associated with the human condition [5]. This model is based on the use of gestational age-matched sera from women with normal pregnancy or $\mathrm{PE}$ in pregnant IL-10/- mice. Using a comparative proteomic screen of normal pregnancy sera and PE sera, we have recently identified the plasma protein transthyretin (TTR) - "transporter of thyroxine and retinol"- as a major pathological factor that is dysregulated in PE [6].

TTR is a $55 \mathrm{kDa}$ homotetrameric protein that transports thyroxine and retinol binding protein from serum and cerebrospinal fluid to the organ sites. Although mainly synthesized in the liver and the choroid plexus of the brain, TTR is also expressed in trophoblast cells of human placenta as early as 6 weeks in pregnancy and throughout gestation $[7,8]$. Thyroxine, a thyroid hormone, is crucial to embryological development of the fetal central nervous system; the fetus solely relies on maternal thyroxine before it secrets thyroid hormones at around 16 weeks gestation [9]. Thus, TTR plays an important role in embryological development of brain through delivery of thyroid hormone to the fetus. TTR is an aggregation-prone protein because of abundance of beta-sheet structure in TTR molecule. TTR aggregates are cytotoxic and are associated with three amyloid diseases: familial amylodotic polyneurophathy, familial amyloidotic cardiomyopathy, and senile systemic amyloidosis. The latter disease is caused by misfolding of wild-type TTR, whereas TTR aggregation in the others is attributed to TTR mutations. Protein misfolding is a process in which protein fails to attain or maintain its biological active confirmation due to missense mutations or intracellular factors such as
$\mathrm{pH}$ changes, oxidative stress, metal ions, etc [10]. Protein misfolding and aggregation are intricately involved in a large number of diseases including cystic fibrosis, Alzheimer's disease, Parkinson's disease, amyotrophic lateral sclerosis, and less familiar diseases such as Gaucher's disease, nephrogenic diabetes insipidus, and CreutzfeldtJakob disease [10]. Our studies have demonstrated that staining with thioflavin S, a fluorescent dye that specifically binds to amyloid, displays an intense signal that overlaps with TTR immunoreactivity from adjacent placental sections from PE, suggestive of an amyloidal nature of TTR deposits. Importantly, sera from PE exhibit increased propensity for TTR specific protein aggregation. Furthermore, administration of TTR immunoprecipitated from PE sera induces PElike features in pregnant IL-10 $10^{--}$mice, and native TTR blocks PE-like features in a "humanized" animal model [6]. Our results strongly suggest that protein misfolding and aggregation involving TTR could be causative events for PE and that aggregated TTR could be used as a biomarker for predicting the onset of PE. The mechanisms by which TTR forms aggregates in the placenta and how these aggregates contribute to the pathogenesis of $\mathrm{PE}$ remain yet to be elucidated.

Endoplasmic reticulum (ER) is an essential organelle for protein synthesis, folding, posttranslational modification (N-linked glycosylation, disulfide bond formation and oligomerization) and secretion. These processes are intricately programmed and rely on the optimum levels of ATP, $\mathrm{Ca}^{2+}$ and an oxidizing environment. Pathological stimuli can interrupt the protein folding process through disturbing metabolic and energy balance, leading to accumulation of misfolded proteins in the ER, a condition termed "ER stress". These pathological stimuli include factors that cause ER calcium depletion, altered glycocylation, nutrient deprivation, oxidative stress, DNA damage, or energy perturbation [11]. Deficient placental perfusion is thought to be the central pathological axis of PE since it induces placental oxidative stress and triggers placental release of inflammatory cytokines, antiangiogenetic factors and placental debris into the maternal circulation, which causes endothelial cell activation [12]. Accumulating evidence has documented that ER stress is associated with early pregnancy loss, intrauterine growth restriction and earlyonset form of PE [12-18]. Since misfolded or aggregated proteins are removed by Endoplasmic reticulum (ER) stress response mechanisms and Unfolded Protein Response (UPR) machinery, it is possible that accumulation of aggregated TTR results from failed UPR and protein degradation mechanisms.

\section{References}

1. Roberts JM, Hubel CA (1999) Is oxidative stress the link in the two-stage model of pre-eclampsia? Lancet 354: 788-789.

2. Redman CW, Sargent IL (2005) Latest advances in understanding preeclampsia. Science 308: 1592-1594. 
Citation: Cheng SB (2014) Is Preeclampsia a Protein Misfolding and Aggregation Disease?. J Trop Dis 2: e108. doi:10.4172/2329-891X. $1000 \mathrm{e} 108$

Page 2 of 2

3. Steegers EA, von Dadelszen P, Duvekot JJ, Pijnenborg R (2010) Preeclampsia. Lancet 376: 631-644.

4. Sunderland N, Hennessy A, Makris A (2011) Animal models of preeclampsia. Am J Reprod Immunol 65: 533-541.

5. Kalkunte S, Boij R, Norris W, Friedman J, Lai Z, et al. (2010) Sera from preeclampsia patients elicit symptoms of human disease in mice and provide a basis for an in vitro predictive assay. Am J Pathol 177: 2387-2398.

6. Kalkunte SS, Neubeck S, Norris WE, Cheng SB, Kostadinov S, et al. (2013) Transthyretin is dysregulated in preeclampsia, and its native form prevents the onset of disease in a preclinical mouse model. Am J Pathol 183: 1425-1436.

7. McKinnon B, Li H, Richard K, Mortimer R (2005) Synthesis of thyroid hormone binding proteins transthyretin and albumin by human trophoblast. J Clin Endocrinol Metab 90: 6714-6720.

8. Patel J, Landers KA, Li H, Mortimer RH, Richard K (2011) Ontogenic changes in placental transthyretin. Placenta 32: 817-822.

9. Chan SY, Vasilopoulou E, Kilby MD (2009) The role of the placenta in thyroid hormone delivery to the fetus. Nat Clin Pract Endocrinol Metab 5: 45-54.

10. Gavrin LK, Denny RA, Saiah E (2012) Small molecules that target protein misfolding. J Med Chem 55: 10823-10843.

11. Li X, Zhang K, Li Z (2011) Unfolded protein response in cancer: the physician's perspective. J Hematol Oncol 4: 8.
12. Burton GJ, Yung HW (2011) Endoplasmic reticulum stress in the pathogenesis of early-onset pre-eclampsia. Pregnancy Hypertens 1: 72-78.

13. Burton GJ, Yung HW, Cindrova-Davies T, Charnock-Jones DS (2009) Placental endoplasmic reticulum stress and oxidative stress in the pathophysiology of unexplained intrauterine growth restriction and early onset preeclampsia. Placenta Suppl A:S43-S48.

14. Gao HJ, Zhu YM, He WH, Liu AX, Dong MY, et al. (2012) Endoplasmic reticulum stress induced by oxidative stress in decidual cells: a possible mechanism of early pregnancy loss. Mol Biol Rep 39: 9179-9186.

15. Jones CJ, Fox H (1980) An ultrastructural and ultrahistochemical study of the human placenta in maternal pre-eclampsia. Placenta 1: 61-76.

16. Kawakami T, Yoshimi M, Kadota Y, Inoue M, Sato M, et al. (2014) Prolonged endoplasmic reticulum stress alters placental morphology and causes low birth weight. Toxicol Appl Pharmacol 275: 134-144.

17. Lian IA, Løset M, Mundal SB, Fenstad MH, Johnson MP, et al. (2011) Increased endoplasmic reticulum stress in decidual tissue from pregnancies complicated by fetal growth restriction with and without pre-eclampsia. Placenta 32: 823-829.

18. Yung HW, Calabrese S, Hynx D, Hemmings BA, Cetin I, et al. (2008) Evidence of placental translation inhibition and endoplasmic reticulum stress in the etiology of human intrauterine growth restriction. Am J Pathol 173: 451-462. 